\title{
Novel popout without novelty
}

\author{
KRISTEN A. DILIBERTO, JEANETTE ALTARRIBA, and W. TRAMMELL NEILL \\ University at Albany, State University of New York
}

\begin{abstract}
Localization of a novel word in an array with several familiar words is typically enhanced relative to localization in an all-novel array (between-array novel popout) and sometimes enhanced relative to familiar words in one-novel arrays (within-array novel popout). Christie and Klein (1996) have questioned the reality of the latter effect, suggesting that it may be an artifact of guessing bias. The present Experiment 1 replicated within-array novel popout with the novel word probed at chance (i.e., on only one quarter of trials). Experiments 2 and 3 demonstrated a similar popout effect for a categorically unrelated word among three categorically related words, despite superior performance on all-related arrays relative to all-unrelated arrays. Repetition of constant sets of words within the experimental context is therefore unnecessary for a popout effect, contrary to assertions by Johnston and Hawley (1994). Interitem associations appear to be sufficient to produce a popout effect; as such, "novel popout" appears to be a misnomer for a phenomenon that does not depend on novelty.
\end{abstract}

The human mind often seems to favor processing of familiar or expected stimuli, as demonstrated, for example, by semantic priming (Neely, 1977), the word-superiority effect (Reicher, 1969), and frequency effects in word identification (Morton, 1969). At other times, however, novel or unexpected stimuli seem to receive preferential processing relative to familiar stimuli, as demonstrated by perceptual habituation (Sokolov, 1963), semantic satiation (Smith, 1984) and the word-inferiority effect (Healy, 1976). In visual search tasks, locating an unfamiliar target in a background of familiar distractors is easier than locating a familiar target in a background of unfamiliar distractors (Reicher, Snyder, \& Richards, 1976). More generally, the mind seems to maintain two simultaneous but opposing biases: to anticipate regularities in the environment, yet to be prepared for violations of those regularities (Grossberg, 1987; Kauffman, 1995).

To resolve this paradox, Johnston and Hawley (1994) proposed the mismatch theory, which has antecedents in Sokolov's (1963) dishabituation theory and Grossberg's (1987) adaptive resonance theory. According to the mismatch theory, opposing biases are instantiated at different levels of processing. Higher level "identity nodes" are presumed to be activated by lower level "iconic nodes." The identity nodes are more highly activated for familiar and expected stimuli and may also activate each other through mutual excitatory connections. However, activation of identity nodes produces a top-down inhibition of

We would like to thank Lauren May and Molly Brown for their as sistance with data collection. We also thank William Johnston, Ray Klein, John Christie, and Cheryl Doland for their comments and suggestions on a previous version of this manuscript. Portions of this article were presented at the 38th annual meeting of the Psychonomic Society, Philadelphia. This work was funded by a faculty research grant awarded to J.A. Correspondence should be addressed to J. Altarriba, Department of Psychology, State University of New York, Albany, NY 12222 (e-mail: ja087@csc.albany.edu). the corresponding iconic nodes. In contrast to the identity nodes, iconic nodes are presumed to laterally inhibit each other. Consequently, if familiar and novel stimuli are simultaneously present, the top-down inhibition of the iconic node for the familiar stimulus tends to disinhibit the iconic node for the unfamiliar stimulus, which in turn further inhibits the iconic node for the familiar stimulus. Hence, perceptual processing of the familiar stimulus is suppressed, and perceptual processing of the unfamiliar stimulus is enhanced (Figure 1).

Johnston and colleagues have relied specifically on the phenomenon of novel popout to support the mismatch theory (Hawley, Johnston, \& Farnham, 1994; Johnston, Hawley, \& Farnham, 1993; Johnston, Hawley, Plewe, Elliott, \& DeWitt, 1990; Johnston \& Schwarting, 1997; Johnston, Schwarting, \& Hawley, 1996). Typically, subjects have been shown arrays of four different words followed by a single-word probe; the subject's task is to indicate the array position in which the probed word appeared. Some of the words are "familiar" in the context of the experiment because they appear repeatedly across trials; other words are "novel" because they appear only once. If an array contains three familiar words and one novel word, localization of the novel word is likely to be enhanced relative to an all-novel array (the between-array novel-popout effect), and localization of familiar words may suffer relative to an all-familiar array (the familiar sink-in effect). In some experiments, the novel word in a one-novel array is localized better than the familiar words (the within-array novel-popout effect), despite higher performance on all-familiar arrays than on all-novel arrays (the baseline effect).

Novel popout apparently depends on the repetition of sets of items together in the same arrays. Johnston et al. (1993, Experiment 3) familiarized participants with repeated quartets of words and then tested arrays in which the familiar words were drawn from the same studied quartet or different quartets. Novel popout occurred only 


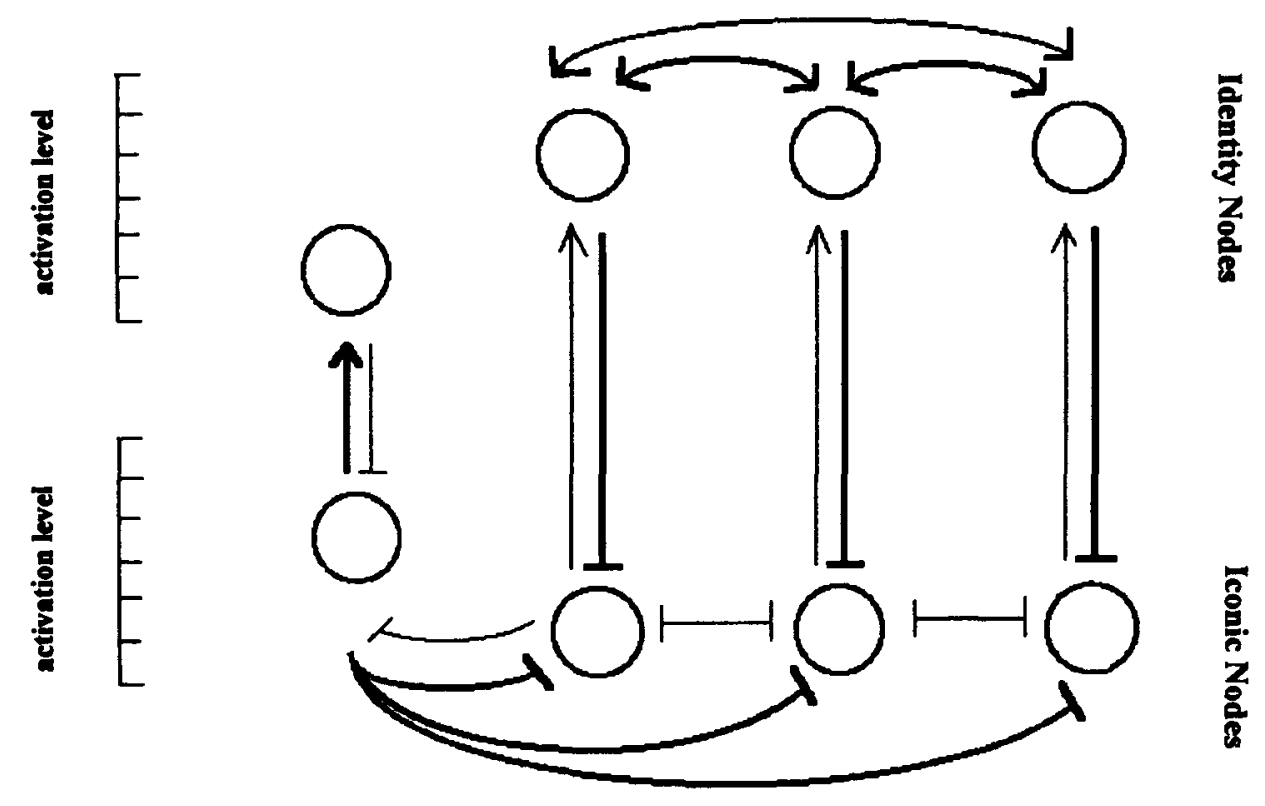

Figure 1. An illustration of the basic components of mismatch theory. Lines terminating with arrows indicate excitatory connections, and those with bars indicate inhibitory connections. The strength of the connection is indicated by the relative thickness of the lines.

if the familiar words were drawn from the same set. Johnston et al. concluded that "associative unitization" of the familiar words in an array is necessary for novel popout. In other words, familiarity of the individual items is not, by itself, sufficient to produce novel popout. Within the mismatch theory (Johnston \& Hawley, 1994), the interitem associations between identity nodes activated together are presumed to mutually enhance their activation levels, thereby increasing their downward inhibition of the iconic nodes.

However, if interitem associations are necessary to produce novel popout, this raises the question of whether interitem associations are, in fact, sufficient to produce popout. If so, "novel popout" is not really due to novelty per se. Rather, experimental familiarization may only serve to establish interitem associations between words that would otherwise be unassociated. Johnston et al. (1993, Experiment 3) concluded that multiple repetitions in the context of the experiment are necessary to obtain the baseline, novel popout, and familiar sink-in effects (at least 15 repetitions for the within-array novel popout). However, if items are associated preexperimentally, familiarization may be unnecessary to produce a popout effect for an unassociated item amidst other associated items.

The primary purpose of the present study (addressed in Experiments 2 and 3 ) was to determine whether or not extra-experimental associations are sufficient to cause novel popout. However, first it is necessary to address a criticism raised by Christie and Klein (1996) regarding the reality of the novel popout effect. They noted that the between-array novel-popout and familiar sink-in effects can be explained by overall processing load: Because the overall difficulty of a one-novel array is less than that of an all-novel array, novel items in one-novel arrays should be processed more easily than items in all-novel arrays. Similarly, because the overall difficulty of a one-novel array is greater than that of an all-familiar array, familiar items in one-novel arrays should be processed less easily than items in all-familiar arrays. Therefore, only withinarray novel popout constitutes valid evidence of a processing advantage for novel versus familiar stimuli. However, in the experiments demonstrating a significant withinarray effect, novel words were probed in half of the onenovel arrays. Therefore, the location of the novel word in one-novel arrays was probed twice as often as would be expected by chance. This inequality might have led subjects to adopt an adaptive strategy of preferentially encoding the location of the novel word.

Johnston et al. (1990, Experiment 4) probed novel words on $25 \%$ of one-novel arrays, consistent with random selection among the four possible locations, but the withinarray novel popout was not statistically significant. Johnston and Schwarting (1997, Experiment 2) did obtain significant within-array novel popout in a replication of this experiment with a much larger sample size $(N=112)$. Given the criticisms by Christie and Klein (1996) of whether between-array effects are interpretable, we first conducted Experiment 1 to ensure that the present procedures and sample size would be sufficient to obtain a within-array popout effect, with all array locations probed with equal probability $(25 \%)$.

\section{EXPERIMENT 1}

\section{Method}

Participants. Thirty-six undergraduate students at the University at Albany, State University of New York, participated for partial fulfillment of a course requirement or for extra credit. Each par- 
ticipant was a native speaker of American English and had normal or corrected-to-normal vision. Each participant was tested individually in a session of approximately $20 \mathrm{~min}$.

Materials and Apparatus. The stimuli were 175 singular nouns, four letters in length, with a Kučera and Francis (1967) frequency range of $1-424$ per million. Fifteen of these were randomly selected to serve as "familiar" items. The remaining 160 words served as "novel" items. The 15 familiar items were assigned to five sets of three words apiece. Each set of three familiar words appeared in 32 different arrays, paired each time with a different novel word, for a total of 160 arrays.

Forty practice arrays were generated using the same sets of familiar items described above and 40 novel items. The novel items were selected from a separate pool of words than those used in the experimental trials.

All experiments were presented on a Crystal Scan monitor interfaced with a Gateway $386 \mathrm{SX} / 25$ PC-compatible computer. Subjects registered their responses on the keys of the numeric keypad on the computer keyboard. The program for the experiment was created using Micro Experimental Laboratory (MEL) psychology software (Schneider, 1988, 1990).

Procedure. Each participant received 40 practice trials and 160 experimental trials. An array of four white rectangular boxes, arranged in the form of a horizontally elongated cross, was centered in the monitor at all times (similar to the procedure used by Johnston et al., 1993). The sequence of events on each trial is displayed in Figure 2. First, participants were presented with a ready signal of four asterisks $\left({ }^{* * * *}\right)$ in each rectangular box for $200 \mathrm{msec}$ (Figure 2a). After an interstimulus interval (ISI) of $500 \mathrm{msec}$, an array of four words (three familiar, one novel) appeared for $200 \mathrm{msec}$
(Figure 2b). The words were centered in each box and appeared in white, lowercase letters. Following a 16-msec ISI, a mask of four uppercase Xs (XXXX) appeared in each location of the rectangle for $100 \mathrm{msec}$ (Figure 2c). Immediately following the mask, the screen cleared and participants were presented with a probe word in the center of the computer screen (Figure $2 \mathrm{~d}$ ). The probe word was one of the items that had appeared in the preceding attention array. Participants were instructed to indicate the location of the word using the numeric keypad located to the right of the computer keyboard. The spatial configuration of the keys corresponded to the locations of the words in the rectangular boxes. Participants were instructed to respond accurately and that speed was not important. In order to encourage accuracy, the computer emitted a 500-msec tone as feedback when an incorrect response was made. Once the participant responded, the probe word disappeared and a blank intertrial interval (ITI) of $500 \mathrm{msec}$ occurred before the next trial began. Participants were given a break after every 40 trials.

Each participant received a different random order of arrays. Each set of four words was randomly assigned to the four locations of the display, and each location was probed with equal frequency. Consequently, familiar words were probed on $75 \%$ of the trials, and novel words were probed on $25 \%$ of the trials.

\section{Results and Discussion}

The proportion of correct localizations was higher for novel words $(M=.85)$ than for familiar words [.82; $t(35)=2.62, p<.01$, two-tailed]. The within-array novelpopout effect was therefore replicated under conditions in which all locations were probed with equal probabil-

\section{(a) WARNING ARRAY $200 \mathrm{~ms}$}

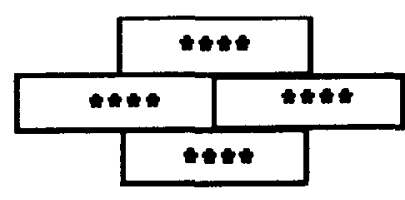

ISI $500 \mathrm{~ms}$

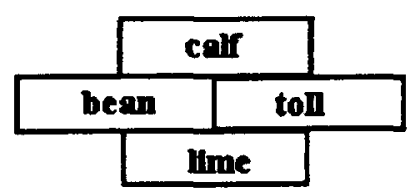

ISI $16 \mathrm{~ms}$

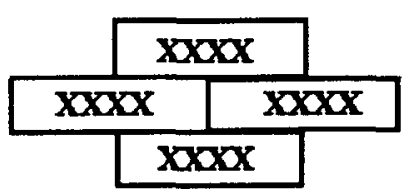

(d) PROBE

lime

Figure 2. An example of the procedure used to produce within-array NPO/FSI effects. 
ity. Given that familiar words were probed on $75 \%$ of trials, one might plausibly expect participants to search for a familiar word instead of a novel word. Nonetheless, the possibility remains that participants adopted a deliberate search for novel singletons, which would give them an advantage in localizability over repeated items. However, Diliberto, Altarriba, and Neill (1998) replicated the within-array popout effect in an experiment that used the same materials as in the present study, but required participants to judge which of four locations contained a brighter word. A quarter of their trials were "catch" trials in which the four words were equiluminant. An analysis of the catch trials revealed that participants selected the novel-word location significantly less frequently than would be expected on the basis of chance $(22.9 \%)$, ruling out a search strategy favoring the novel word. Given the similarity of results and procedures to those of the present experiment, it seems unlikely that participants employed a singleton-search strategy here.

\section{EXPERIMENT 2}

\section{Method}

Participants. Forty-two undergraduate students at the University at Albany, State University of New York, participated either to fulfill a course requirement or to receive extra credit. All were native speakers of American English.

Materials and Apparatus. Stimuli were 180 singular nouns selected from the Battig and Montague (1969) norms for category membership, with an average length of 4.3 and with a Kučera and Francis (1967) frequency range of 1-660 per million. Six of the most frequently mentioned words from each of 30 categories were selected. For each category, the six selected words were assigned to two sets of three words, yielding 60 categorized sets of words. An additional 60 words, with an average length of 4.3 and with a frequency range of 1-808 per million (Kučera \& Francis, 1967) were selected to serve as uncategorized items. Four-word arrays were constructed by assigning one uncategorized word to each categorized set of three words, such that (1) the length of the uncategorized word was equal to the average of the three categorized words, and (2) it was not associated to the categorized words.

Twelve practice arrays were generated using 12 sets of three words drawn from categories that were not used in the experimental phase, coupled with 12 uncategorized words that met the same criteria as for the experimental arrays.

Other aspects of materials and apparatus were identical to those in Experiment 1.

Procedure. Each participant received 12 practice trials and 60 experimental trials. Unlike Experiment 1, every word appeared only once in the course of the experiment. All other aspects of the procedure were identical to that of Experiment 1.

\section{Results and Discussion}

The proportion of correct localizations was greater for uncategorized words (.79) than for categorized words $[.75 ; t(41)=2.11, p<.05$, two-tailed]. In other words, an uncategorized item among categorized items produces a "popout" analogous to that produced by a novel item among familiar items. As such, interitem associations appear to be sufficient to produce a popout effect; exper- imental familiarity versus novelty does not seem to be a necessary condition for such effects. Hence, "novel popout" may be a misnomer - it is not the novelty per se that causes a processing advantage.

Experiments on novel versus familiar items have repeatedly found that items in all-familiar arrays are localized more accurately than items in all-novel arrays (the baseline effect). Therefore, differences in baseline performance cannot account for the within-array novel popout effect. However, it has not been established that items in all-categorized arrays would be localized better than items in all-uncategorized arrays. Therefore, the possibility remains that the popout effect for uncategorized items in Experiment 2 is an artifact of higher baseline performance. In addition, because different items were used in the categorized and uncategorized conditions, we cannot rule out the possibility of item-selection effects. That is, categorized and uncategorized words were selected by somewhat different criteria. It is possible that the two sets of words differed in some uncontrolled aspect (e.g., distinctiveness, meaningfulness, concreteness) that might have favored identification of the uncategorized words.

In order to establish the relative baseline effects and to rule out item-selection effects, Experiment 3 compared exactly the same materials in all-categorized versus alluncategorized arrays. If the materials were biased to favor processing of the uncategorized items, then performance on the uncategorized arrays should be superior to that for the categorized arrays. On the other hand, if interitem associations tend to enhance the activation of identity nodes in the same manner as familiarization in the experimental context, then categorized arrays should result in better performance than uncategorized arrays, just as all-familiar arrays yield better performance than all-novel arrays (baseline effect).

\section{EXPERIMENT 3}

\section{Method}

Participants. Sixty undergraduate students at the University at Albany, State University of New York, participated to fulfill a course requirement.

Materials and Apparatus. The 180 category exemplars and 60 uncategorized items from Experiment 2 served as critical target items. An additional 60 words were selected to serve as filler items, 2 from each of the 30 categories. To create 60 all-categorized arrays, each novel item in an Experiment 2 array was replaced by a filler item from the same category. The 60 uncategorized items from Experiment 2 were recombined to form 15 all-uncategorized arrays. In Experiment 2, categorized words were probed three times as often as uncategorized words. In order to maintain this same ratio, five additional all-uncategorized filler arrays were created from 20 more words selected from the Kučera and Francis (1967) word frequency norms.

To create the practice trials, an additional 12 words were selected to serve as filler items. Each uncategorized word in Experiment 2 practice was replaced by a filler word from the same category to make the all-categorized arrays. The 12 uncategorized items were recombined to form three all-uncategorized arrays. In order to 
maintain the same ratio of categorized and uncategorized items, one additional all-uncategorized filler array was created from four more words selected from Kučera and Francis (1967).

Procedure. In the all-categorized arrays, the probed word was always one of the three that had been included in Experiment 2 . Although a new word was necessarily probed in the five uncategorized filler arrays, these data were not analyzed. All other aspects of the procedure were identical to those of Experiment 2.

\section{Results and Discussion}

The proportion of correct localizations was higher for all-categorized arrays $(.83)$ than for all-uncategorized arrays $[.80 ; t(59)=2.07, p<.05$, two-tailed $]$, analogous to the baseline effect found for all-familiar versus all-novel arrays. Therefore, the superior performance on the same uncategorized items in the mixed arrays of Experiment 2 cannot be attributed to item-selection effects.

The overall level of performance between the two experiments was similar (an unweighted mean of .77 in Experiment 2 and of .82 in Experiment 3). The difference appears to be due more to the categorized items (.75 vs. $.83)$ than to the uncategorized items $(.79$ vs. .80$)$. This suggests that the "categorized sink-in effect" was stronger than the "uncategorized popout effect." However, given the criticisms raised by Christie and Klein (1996) of between-array comparisons, these differences must be regarded as merely suggestive. It may also be noted that the overall level of performance was somewhat higher than in comparable experiments by Johnston and colleagues (typically less than .70; Johnston et al., 1993). This is probably due to the use of slightly longer exposure durations (216 msec here vs. $200 \mathrm{msec}$ in Johnston's experiments).

\section{GENERAL DISCUSSION}

Christie and Klein (1996) questioned the reality of within-array novel popout on the grounds that significant effects have been obtained only if the location of the novel word is probed more frequently than expected by chance. However, the present Experiment 1 revealed a within-array novel-popout effect when the location of the novel word was probed with only chance probability (.25), replicating Johnston and Schwarting (1997, Experiment 2). Thus, within-array novel popout appears to be a genuine, replicable phenomenon.

In addition to questioning the reality of the novel popout effect, Christie and Klein (1996) raised questions regarding the theoretical interpretation of the effect. They argued that the effects can be explained without reference to orienting of attention to the novel item. They noted that the word-localization task requires retrieval of identity information from memory when the probe word is presented. It is therefore ambiguous as to whether superior performance on the novel word is caused by attentional orienting during the display or by an advantage in memory retrieval. Christie and Klein argued that attentional orienting must be inferred from judgments of some attribute that is independent of the word's identity.
However, as discussed earlier, Diliberto et al. (1998) used a brightness discrimination procedure to investigate the locus of the novel popout effect. Because localization of brightness does not inherently require reference to word identity and because no retrospective retrieval is occasioned by a subsequent probe, superior performance on novel words would support an attentional explanation of the effect. Diliberto et al. (Experiments 1 and 2) replicated within-array novel popout effects similar in magnitude to those found in the present experiments on word localization, thereby supporting an attentional explanation for the present set of results.

Johnston and Hawley (1994) asserted,

The effects require that the familiar field objects be collectively, rather than just individually, familiar and contextually or episodically, rather than just preexperimentally, interassociated. For example, the effects were not observed when the field objects either had appeared many times in the context of the experiment but never together or were semantically related but had not appeared previously in the context of the experiment. (p. 57) ${ }^{1}$

However, Experiment 2 revealed that localization of a categorically unrelated word among three categorically related words was superior to localization of the categorically related words, despite the advantage of all-related arrays over all-uncategorized arrays (Experiment 3 ). Thus, it appears that interitem associations, rather than familiarization in the context of the experiment, are both necessary and sufficient to produce a popout effect.

It may be noted that the uncategorized-popout effect obtained in Experiment 2 bears some similarity to categorical popout effects obtained in more typical visual search tasks (e.g., Egeth, Jonides, \& Wall, 1972; Francolini \& Egeth, 1979; Gleitman \& Jonides, 1976). In such tasks, judging the presence or absence of a prespecified target may be faster or less affected by number of distractors if the target belongs to a different category than the distractors (e.g., searching for a letter among digits). Theoretically, participants might test for the presence or absence of activation in the target category or suppress activation in the distractor category (if known). However, in the present experiments, participants could not anticipate the category of either the probed word or the other words in the display.

Although the empirical result of Experiment 2 contradicts the assertion by Johnston and Hawley (1994) that preexperimental associations are insufficient to produce a popout effect, the result may actually support their mismatch theory. Given that all-categorized arrays are easier than all-uncategorized arrays (Experiment 3), superior localization of the uncategorized word in mixed arrays indicates that some interaction between processing of categorized words and concurrent processing of the uncategorized word is responsible for the effect. It is precisely this type of interaction that is embodied in the mismatch theory to explain superior performance on the novel item in a one-novel array despite inferior performance on all- 
novel versus all-familiar arrays. Johnston et al. (1993, Experiment 3 ) concluded that "associative unitization" is necessary to produce novel popout. Theoretically, the interitem associations would mutually heighten the activation of the identity nodes, which would in turn drive the downward inhibition of the iconic nodes. If items are not preexperimentally associated, then repetition of the items as constant sets in the experiment serves to strengthen these interitem associations. In essence, the participants are learning new categories based on the cooccurrence of the words. However, if items are preexperimentally associated, familiarity versus novelty in the context of the experiment may be irrelevant.

\section{REFERENCES}

Battig, W. F., \& Montague, W. E. (1969). Category norms for verbal items in 56 categories: A replication and extension of the Connecticut category norms. Journal of Experimental Psychology Monographs, 80, $(3$, Pt. 2).

Christie, J., \& KLeIN, R. M. (1996). Assessing the evidence for novel popout. Journal of Experimental Psychology: General, 125, 201-207.

Diliberto, K. A., Altarriba, J., \& Neill, W. T. (1998). Novel popout and brightness discrimination: Attention as "cause" or "effect?" Unpublished manuscript.

Egeth, H. E., Jonides, J., \& Wall, S. (1972). Parallel processing of multielement displays. Cognitive Psychology, 3, 674-698.

Francolini, C. M., \& Egeth, H. E. (1979). Perceptual selectivity is task dependent: The pop-out effect poops out. Perception \& Psychophysics, 25, 99-110.

Gleitman, H., \& Jonides, J. (1976). The cost of categorization in visual search: Incomplete processing of targets and field items. Perception \& Psychophysics, 20, 281-288.

GROSSBERG, S. (1987). Competitive learning: From interactive activation to adaptive resonance. Cognitive Science, 11, 23-63.

Hawley, K. J., Johnston, W. A., \& FarnhaM, J. M. (1994). Novel popout with nonsense strings: Effects of predictability of string length and spatial location. Perception \& Psychophysics, 55, 261-268.

HEALY, A. F. (1976). Detection errors on the word the: Evidence for reading units larger than words. Journal of Experimental Psychology: Human Perception \& Performance, 2, 235-242.

Johnston, W. A., \& HAWLey, K. J. (1994). Perceptual inhibition of expected inputs: The key that opens closed minds. Psychonomic Bulletin \& Review, 1, 56-72.

Johnston, W. A., Hawley, K. J., \& Farnham, J. M. (1993). Novel popout: Empirical boundaries and tentative theory. Journal of Experimental Psychology: Human Perception \& Performance, 19, 140-153.

Johnston, W. A., Hawley, K. J., Plewe, S. H., Elliott, J. M., \& DeWITT, M. J. (1990). Attention capture by novel stimuli. Journal of Experimental Psychology: General, 119, 397-411.

JohNSTON, W. A., \& SchWARTING, I. S. (1997). Novel popout: An enigma for conventional theories of attention. Journal of Experimental Psychology: Human Perception \& Performance, 23, 622-631.

Johnston, W. A., Schwarting, I. S., \& Hawley, K. J. (1996). Novel popout, perceptual inhibition, and the stability-plasticity dilemma. In A. F. Kramer, M. G. H. Coles, \& G. D. Logan (Eds.), Converging operations in the study of visual selective attention (pp. 315-335). Washington, DC: American Psychological Association.

KaUfFMAN, S. (1995). At home in the universe. New York: Oxford University Press.

Kučera, J., \& Francis, W. N. (1967). Computational analysis of present-day American English. Providence, RI: Brown University Press.

MORTON, J. (1969). Interaction of information in word recognition. Psychological Review, 76, 165-178.

NeELY, J. H. (1977). Semantic priming and retrieval from lexical memory: Roles of inhibitionless spreading activation and limited capacity attention. Journal of Experimental Psychology: General, 106, 226-254.

Reicher, G. M. (1969). Perceptual recognition as a function of meaningfulness of stimulus material. Journal of Experimental Psychology, 81, 275-280.

Reicher, G. M., SNYder, C. R., \& Richards, J. T. (1976). Familiarity of background characters in visual scanning. Journal of Experimental Psychology: Human Perception \& Performance, 2, 522-530.

SCHNEIDER, W. (1988). Micro Experimental Laboratory: An integrated system for IBM PC compatibles. Behavior Research Methods, Instruments, \& Computers, 20, 206-217.

SCHNEIDER, W. (1990). MEL users' guide: Computer techniques for real time experimentation. Pittsburgh: Psychology Software Tools.

SoKoLov, E. N. (1963). Higher nervous functions: The orienting reflex. Annual Review of Psychology, 25, 545-580.

SMITH, L. C. (1984). Semantic satiation affects category membership decision time but not lexical priming. Memory \& Cognition, 16, 483-488.

\section{NOTE}

1. The discussion by Johnston and Hawley (1994) here is rather vague since it occurs in the context of describing between-array novel popout, within-array novel popout, familiar sink-in, and baseline effects together. They did not cite a specific experiment in which preexperimental interassociation was insufficient to produce a popout effect.

(Manuscript received May 28, 1997; revision accepted for publication October $21,1997$. 